\title{
VIRULENSI BERBAGAI ISOLAT JAMUR ENTOMOPATOGEN METARHIZIUM SPP. TERHADAP HAMA PENGGEREK BUAH KAKAO CONOPOMORPHA CRAMERELLA SNELL. (LEPIDOPTERA: GRACILLARIIDAE)
}

\author{
Trizelia $^{1}$, Nurbailis ${ }^{1}, \&$ Dina Ernawati ${ }^{2}$ \\ ${ }^{1}$ Jurusan Hama dan Penyakit Tumbuhan Fakultas Pertanian Universitas Andalas, Kampus Limau Manis, Padang 25163 \\ ${ }^{2}$ Balai Besar Perbenihan dan Proteksi Tanaman Perkebunan Surabaya, \\ Jl. Raya Mojoagung No.52, Jombang 61482 \\ E-mail: trizelia@yahoo.com
}

\begin{abstract}
Virulence of various Metarhizium spp. (Deuteromycotina: Hyphomycetes) isolates on cocoa pod borrer pest, Conopomorpha cramerella Snell. (Lepidoptera: Gracillariidae). In Indonesia, Conopomorpha cramerella Snell. (Lepidoptera : Gracillariidae) is a serious pest of cocoa. Entomopathogens such as Metarhizium spp. (Deuteromycotina: Hyphomycetes) can be used to control this pest as an alternative to chemical insecticides. The purpose of this research was to study the virulence of isolates of Metarhizium spp. to pupae of C. cramerella. Nine isolates of Metarhizium spp each with $10^{7}$ conidia/ml rate were used in the experiment. Pupal mortality was recorded daily. The results showed that isolate MetApCi from chili rhizosphere had the highest virulence causing $96.67 \%$ mortality of $C$. cramerella pupae and with an $\mathrm{LT}_{50}$ of 3.04 days.
\end{abstract}

Key words: cocoa, Conopomorpha cramerella, Metarhizium spp., pupae, virulence

ABSTRAK

Virulensi Berbagai Isolat Jamur Entomopatogen Metarhizium spp. Terhadap Hama Penggerek Buah Kakao Conopomorpha Cramerella Snell. (Lepidoptera: Gracillariidae). Metarhizium spp. (Deuteromycotina: Hyphomycetes) merupakan salah satu jenis jamur entomopatogen yang potensial untuk mengendalikan hama penggerek buah kakao (PBK) Conopomorpha cramerella Snell. (Lepidoptera: Gracillariidae). Usaha untuk meningkatkan keberhasilan penggunaan Metarhizium spp. sebagai agens pengendali hayati $C$. cramerella di lapangan memerlukan isolat atau strain yang virulensinya tinggi dan cepat membunuh serangga hama. Penelitian bertujuan untuk mendapatkan isolat jamur Metarhizium spp yang virulen terhadap hama PBK. Pada percobaan ini digunakan pupa C. cramerella dan 9 isolat Metarhizium spp. yang berasal dari berbagai rizosfer tanaman. Kerapatan konidia Metarhizium spp yang digunakan adalah $10^{7} \mathrm{konidia} / \mathrm{ml}$. Hasil penelitian menunjukkan bahwa isolat MetApCi yang diisolasi dari rizosfer tanaman cabai lebih virulen dibanding isolat lain terhadap pupa $C$. cramerella dengan menghasilkan mortalitas pupa sebesar 96,67\% dan memiliki nilai LT50 tersingkat yaitu 3,04 hari.

Kata kunci : Conopomorpha cramerella, kakao, Metarhizium spp, pupa, virulensi,

\section{PENDAHULUAN}

Kakao (Theobroma cacao L.) merupakan salah satu komoditas perkebunan yang memiliki peranan cukup penting bagi perekonomian nasional, khususnya sebagai sumber pendapatan dan devisa negara. Di tingkat dunia, Indonesia dengan produksi tahunan mencapai 700 ribu ton merupakan salah satu negara yang membudidayakan tanaman kakao paling luas di dunia, dan merupakan produsen kakao terbesar ketiga setelah Ivory Coast dan Ghana. Masalah yang dihadapi kakao Indonesia adalah rendahnya produktivitas (di bawah $900 \mathrm{~kg} / \mathrm{ha} / \mathrm{thn}$ dari rata-rata potensi sebesar $2.000 \mathrm{~kg} / \mathrm{ha} / \mathrm{thn})$. Di antara faktor penyebab rendahnya produktivitas kakao, mayoritas disebabkan antara lain karena penggunaan bahan tanaman yang kurang optimal, umur tanaman, serta masalah hama dan penyakit (Wahyudi \& Misnawi, 2007).

Sulistyowati (2009) menyatakan bahwa tanaman kakao merupakan tanaman yang disukai oleh berbagai jenis organisme hama. Kelompok serangga merupakan salah satu jenis hama yang paling banyak menyerang tanaman kakao. Di Indonesia, jumlah serangga merupakan kelompok hama yang populasinya 
paling banyak (lebih dari 130 spesies). Hama utama yang menyerang tanaman kakao di Sumatera Barat adalah penggerek buah kakao/PBK (Conopomorpha cramerella Snell.; Lepidoptera, Gracillariidae), kepik pengisap buah (Helopeltis antonii Sign.; Hemiptera, Miridae), serta tupai (Disbun Sumbar, 2011).

Hama PBK dapat menurunkan hasil panen sampai 82,2\% (Wardoyo, 1982). Selain itu, PBK juga dapat menurunkan kualitas hasil panen akibat menurunnya mutu fisik biji, meningkatnya kandungan sampah dan kandungan kulit ari, serta menurunnya rendemen dan berat jenis biji kakao (Depparaba, 2002). Hingga bulan Maret 2011, areal tanaman kakao di Sumatera Barat yang terserang PBK mencapai 944 ha dengan nilai kerugian sebesar Rp.509.804.000 (Disbun Sumbar, 2011).

Salah satu metode penanggulangan PBK adalah pengendalian hayati dengan menggunakan jamur entomopatogen Metarhizium spp. Hasil penelitian Hamdani (2008) menunjukkan bahwa aplikasi isolat Metarhizium spp. yang berasal dari rizosfer pertanaman kakao di Pariaman pada konsentrasi $10^{8}$ konidia/ml setelah 8 hari inokulasi mampu menyebabkan kematian prapupa $C$. cramerella hingga $100 \%$. Hasil penelitian Prayogo \& Tengkano (2004) menunjukkan bahwa larva Spodoptera litura yang dipapar konidia Metarhizium anisopliae pada konsentrasi $10^{7}$ konidia/ $\mathrm{ml}$ mampu mengalami kematian hingga 83,33\% pada hari ke-12 setelah aplikasi. Metarhizium bruneum pada konsentrasi $5 \times 10^{5}$ konidia/ml mampu mengakibatkan mortalitas rayap Captotermes gestroi (Isoptera) lebih dari $80 \%$ (Desyanti et al., 2007). Usaha untuk meningkatkan keberhasilan penggunaan Metarhizium spp. sebagai agens pengendali hayati $C$. cramerella di lapangan memerlukan isolat atau strain yang virulensinya tinggi, cepat membunuh serangga hama dan mampu bertahan di ekosistem pertanian. Tujuan dari penelitian ini adalah untuk mendapatkan isolat cendawan Metarhizium spp yang virulen terhadap hama PBK.

\section{METODE PENELITIAN}

Tempat dan Waktu. Penelitian ini dilaksanakan di Laboratorium Pengendalian Hayati Jurusan Hama dan Penyakit Tumbuhan Fakultas Pertanian Universitas Andalas (Faperta Unand) Padang pada Desember 2011 - Maret 2012.

Jamur Metarhizium spp. Isolat Metarhizium spp yang digunakan dalam penelitian ini merupakan koleksi Laboratorium Pengendalian Hayati Jurusan Hama dan Penyakit Tumbuhan Faperta Unand dan dari tanah di sekitar rizosfer pertanaman kakao di Pariaman dan Lima Puluh Kota (Tabel 1). Seluruh isolat ditumbuhkan pada medium Sabauraud dextrose agar (SDAY). Isolasi Metarhizium spp. dari tanah dilakukan dengan mengambil tanah di sekitar rizosfer pertanaman kakao. Pengambilan tanah dilakukan dengan cara penggalian tanah pada kedalaman 10-15 cm dengan menggunakan sekop tangan kecil. Sampel tanah dimasukkan ke dalam kantong plastik dan dibawa ke laboratorium untuk dilakukan isolasi Metarhizium spp.

Isolasi jamur dari tanah dilakukan dengan metode perangkap umpan (bait method) menggunakan larva Tenebrio molitor. Sampel tanah dari masing-masing lokasi dibersihkan dari akar tanaman, dihaluskan kemudian diayak dengan ayakan 600 mesh. Selanjutnya sampel tanah tersebut sebanyak 500 gram dimasukkan ke dalam kotak plastik berukuran $15 \mathrm{~cm}$ x $10 \mathrm{~cm}$ x 10 $\mathrm{cm}$. Tanah dilembabkan dengan air steril, kemudian 10 ekor larva Tenebrio molitor instar 5 yang baru berganti kulit dimasukkan. Kotak plastik kemudian diinkubasikan pada suhu kamar $\left(25^{\circ} \mathrm{C}\right)$ selama 10 hari. Pengamatan larva Tenebrio mati terinfeksi dilakukan

Tabel 1. Sumber isolat Metarhizium spp. yang digunakan dalam penelitian

\begin{tabular}{llll}
\hline Isolat & Sumber & Lokasi & Asal isolat \\
\hline MetApBm & Rizosfer bawang merah & Alahan Panjang (Solok) & Laboratorium \\
MetApKb & Rizosfer kubis & Alahan Panjang (Solok) & Laboratorium \\
MetHKo & Rizosfer kakao & Halaban (Lima Puluh Kota) & Laboratorium \\
MetKbCi & Rizosfer cabai & Koto Baru (Tanah Datar) & Laboratorium \\
MetApBd & Rizosfer bawang daun & Alahan Panjang (Solok) & Laboratorium \\
MetApCi & Rizosfer cabai & Alahan Panjang (Solok) & Laboratorium \\
MetAKo & Rizosfer kakao & Lubuk Basung (Agam) & Laboratorium \\
MetPKo & Rizosfer kakao & Pariaman & Koleksi langsung \\
MetLkKo & Rizosfer kakao & Guguak (Lima Puluh Kota) & Koleksi langsung \\
\hline
\end{tabular}


setiap hari. Larva yang mati diambil dan disterilkan permukaan dengan alkohol $70 \%$ dan dibilas 3 kali dengan air steril. Selanjutnya dimasukkan ke dalam cawan petri yang telah dialasi dengan kertas tisu lembab dan diinkubasi selama 12 hari. Isolasi jamur dari larva yang terinfeksi dilakukan dengan cara mengambil (mencuplik) konidia jamur yang tumbuh di bagian permukaan tubuh larva dengan menggunakan jarum ose dan cuplikan ditumbuhkan pada medium SDAY dan diinkubasi selama 7 hari pada suhu $25{ }^{\circ} \mathrm{C}$. Jamur entomopatogen yang tumbuh, diidentifikasi secara makroskopis dan mikroskopis dengan menggunakan kunci identifikasi Barnett \& Hunter (1972).

Penyediaan Serangga Uji. Serangga uji berupa pupa C. cramerella dikumpulkan dari buah-buah kakao terserang hama tersebut yang belum berlubang. Semua buah terserang dibawa ke laboratorium, diletakan di atas meja yang sebelumnya telah dialas karung plastik. Tumpukan buah kakao terserang $C$. cramerella ditutup dengan daun kakao, kemudian ditutup lagi dengan karung plastik. Pengamatan dilakukan setiap hari untuk mengetahui ada tidaknya pupa (Suntoro et al., 2003; Hamdani, 2008). Pupa yang ditemukan dan melekat pada daun dipanen, yaitu dengan memotong bagian daun kakao yang ditempeli pupa dengan ukuran 2,5 cm x 2,5 $\mathrm{cm}$. Semua pupa yang dipanen kemudian dikeluarkan dari kokonnya dan ditempatkan pada cawan petri (Hamdani, 2008).

Penyiapan Suspensi Konidia. Isolat Metarhizium spp. diperbanyak pada medium SDAY dalam cawan petri pada suhu $25^{\circ} \mathrm{C}$ selama 15 hari. Konidia cendawan dipanen dengan cara menambahkan $10 \mathrm{ml}$ akuades steril dan $0,05 \%$ Tween 80 sebagai bahan perata ke dalam cawan petri itu. Konidia dilepaskan dari medium dengan kuas halus. Suspensi disaring dan konsentrasi konidia dihitung dengan menggunakan haemocytometer.

Uji Virulensi. Pupa C. cramerella diinokulasi dengan konidia Metarhizium spp. Percobaan disusun dalam rancangan acak lengkap (RAL) dengan 10 perlakuan dan 3 ulangan. Perlakuan terdiri atas sembilan isolat Metarhizium spp. dan kontrol. Konsentrasi konidia dari masing-masing isolat yang digunakan adalah $10^{7}$ konidia/ $\mathrm{ml}$. Setiap unit percobaan terdiri dari 10 ekor serangga uji yaitu pupa $C$. cramerella yang diletakan dalam cawan petri berdiameter $9 \mathrm{~cm}$. Pupa-pupa disemprot dengan suspensi Metarhizium spp. sesuai perlakuan. Aplikasi Metarhizium spp. menggunakan hand sprayer dengan tiga kali semprot per unit percobaan. Setelah penyemprotan, pupa dipindahkan ke cawan petri steril yang dialasi kertas tisu lembab. Pengamatan dilakukan terhadap mortalitas pupa, persentase imago terbentuk dan sporulasi Metarhizium spp. pada pupa. Data hasil percobaan diolah dengan sidik ragam pada taraf nyata 5\% dan dilanjutkan dengan pengujian nilai tengah menggunakan uji Tukey (HSD). Penentuan nilai waktu letal $\left(\mathrm{LT}_{50}\right)$ untuk masing-masing isolat dilakukan dengan analisis probit menggunakan program Statistical Analysis System (SAS) versi 6.12.

\section{HASIL DAN PEMBAHASAN}

Mortalitas Pupa C. cramerella. Hasil uji virulensi berbagai isolat Metarhizium spp. terhadap pupa $C$. cramerella menunjukkan bahwa seluruh isolat Metarhizium spp. menyebabkan kematian pupa $C$. cramerella. Virulensi antar isolat Metarhizium spp. yang diuji tidak nyata tetapi virulensi setiap isolat berbeda nyata dengan kontrol $(\mathrm{F}=18,7, \mathrm{db}=9 ; 20, \mathrm{P}=0,0000)$. Tabel 2 menunjukkan perbandingan virulensi antar isolat Metarhizium spp.dan kontrol.

Mortalitas pupa $C$. cramerella setelah 8 hari aplikasi Metarhizium spp. berkisar antara 70,00-96,30\% yang lebih tinggi daripada mortalitas pupa $C$. cramerella pada kontrol. Hal ini menunjukkan bahwa semua isolat Metarhizium spp. yang diuji bersifat virulen terhadap pupa $C$. cramerella. Artinya pupa $C$. cramerella rentan terhadap Metarhizium spp.

Berdasarkan Tabel 2 juga dapat dilihat bahwa sumber isolat Metarhizium spp. tidak berpengaruh nyata terhadap mortalitas pupa $C$. cramerella. Isolat Metarhizium spp. yang digunakan tidak bersifat spesifik dan isolat yang virulen terhadap $C$. cramerella bisa diperoleh dari sumber lain. Daoust \& Roberts (1982) melaporkan bahwa tidak ada korelasi antara asal inang dan geografi dari isolat dengan virulensi isolat $M$. anisopliae terhadap larva Culex pipiens pipiens Linn. (Diptera: Culicidae).

Perkembangan mortalitas pupa $C$. cramerella setelah aplikasi jamur Metarhizium spp. pada masingmasing isolat dapat dilihat pada Gambar 1. Kematian pupa $C$. cramerella umumnya mulai terjadi 2 hari setelah aplikasi Metarhizium spp. kecuali pada isolat MetHKo dan MetApKb serta kontrol yang terjadi pada 3 hari setelah aplikasi. Jumlah pupa $C$. cramerella yang mati mengalami peningkatan tajam mulai pada hari ke-3 setelah aplikasi hingga akhir pengamatan 8 hari setelah aplikasi.

Kematian pupa $C$. cramerella diduga diakibatkan terjadinya defisiensi nutrien, adanya toksin yang dikeluarkan oleh jamur, dan terjadinya kerusakan jaringan 
Tabel 2. Mortalitas pupa C. cramerella setelah 8 hari aplikasi Metarhizium spp. dengan konsentrasi 107 konidia/ $\mathrm{ml}$

\begin{tabular}{cc}
\hline Isolat & Rata-rata mortalitas pupa C. cramerella $(\%) \pm \mathrm{SD}$ \\
\hline MetAKo & $96,67 \pm 5,77 \mathrm{a}$ \\
MetApCi & $96,67 \pm 5,77 \mathrm{a}$ \\
MetHKo & $93,33 \pm 5,77 \mathrm{a}$ \\
MetApKb & $93,33 \pm 11,55 \mathrm{a}$ \\
MetLkKo & $90,00 \pm 10,00 \mathrm{a}$ \\
MetKbCi & $86,67 \pm 11,55 \mathrm{a}$ \\
MetApBm & $83,33 \pm 15,28 \mathrm{a}$ \\
MetApBd & $80,00 \pm 10,00 \mathrm{a}$ \\
MetPKo & $70,00 \pm 10,00 \mathrm{a}$ \\
Kontrol & $16,67 \pm 5,77 \mathrm{~b}$ \\
\hline
\end{tabular}

Angka yang diikuti huruf yang sama dalam kolom yang sama menunjukkan tidak berbeda nyata menurut uji Tukey (HSD) pada $\alpha=0,05$.

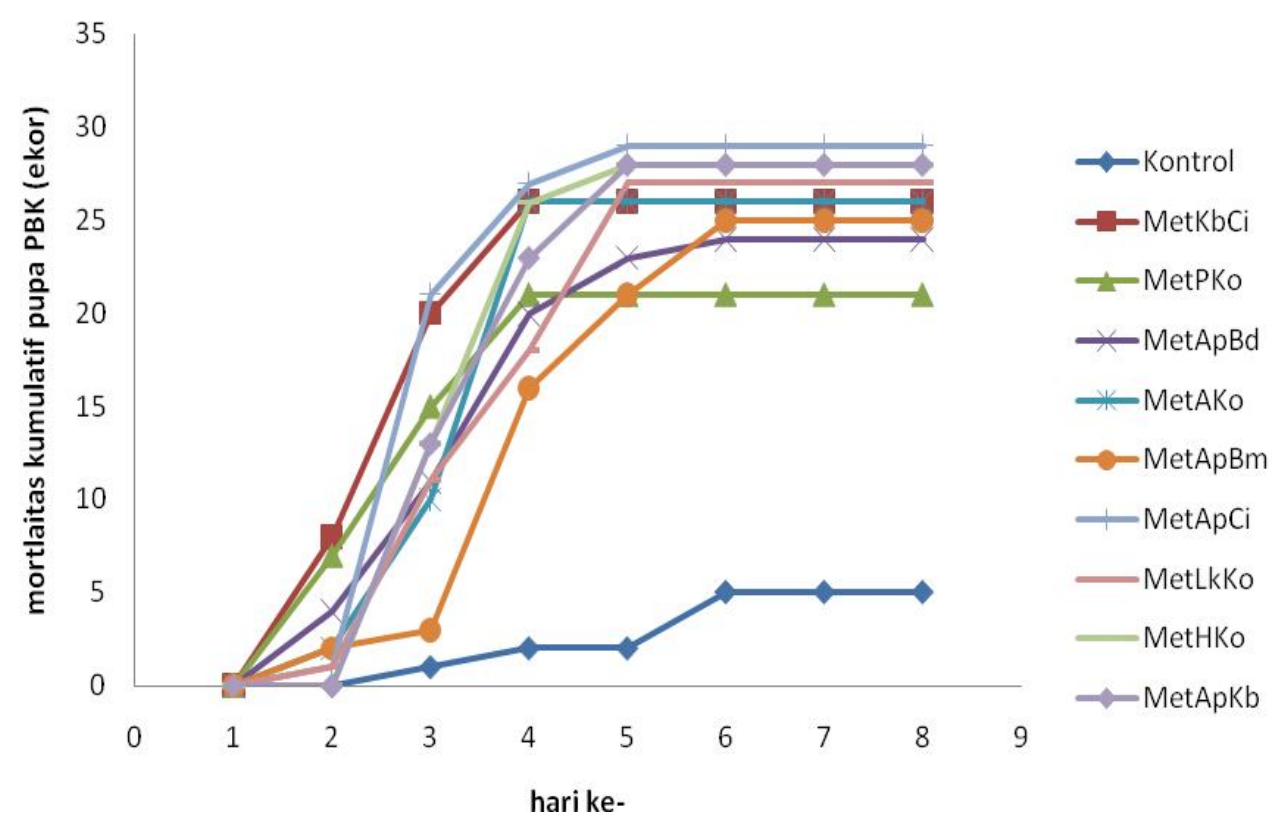

Gambar 1. Mortalitas kumulatif pupa C. cramerella setelah diperlakukan dengan isolat-isolat Metarhizium spp.

dalam tubuh serangga. Ferron (1981) dan Tanada \& Kaya (1993) mengemukakan bahwa Metarhizium spp. menghasilkan toksin yaitu destruksin. yang bisa membunuh serangga inang dengan merangsang atau memacu terjadinya kerusakan jaringan serangga, kehilangan keutuhan struktural membran dan kemudian terjadi dehidrasi. Kematian juga dapat terjadi akibat penyumbatan spirakel oleh massa jamur entomopatogen sebelum serangan jamur pada hemosol.

Nilai LT50. Lama waktu yang dibutuhkan oleh masingmasing isolat Metarhizium spp. untuk mematikan 50\% populasi pupa $C$. cramerella dapat dilihat pada nilai LT50. Berdasarkan nilai LT50 terlihat ada perbedaan antar isolat (Tabel 3).

Pada Tabel 3 terlihat bahwa untuk mematikan $50 \%$ pupa $C$. cramerella dibutuhkan waktu antara 3,044,82 hari. Nilai LT50 yang lebih singkat menunjukkan tingginya patogenisitas atau virulensi patogen dan sebaliknya, nilai LT50 yang panjang menunjukkan rendahnya tingkat patogenisitas (Tanada \& Kaya, 1993). Isolat MetApCi memiliki nilai LT50 tersingkat dibandingkan dengan isolat lain (3,04 hari). Hal ini berarti bahwa dari seluruh isolat yang diuji, isolat MetApCi merupakan isolat yang paling virulen terhadap pupa 
C. cramerella. Neves \& Alves (2004) menyatakan bahwa waktu kematian serangga dipengaruhi oleh dosis aplikasi dan virulensi dari isolat.

Perbedaan nilai LT50 antar isolat Metarhizium spp. juga dilaporkan dalam penelitian Ginting (2008) yang menyatakan bahwa isolat Metarhizium brunneum lebih virulen $\left(\mathrm{LT}_{50}=2,04\right.$ hari) terhadap rayap Schedorhinotermes javaniscus dibanding isolat $M$. anisopliae $\left(\mathrm{LT}_{50}=2,21\right.$ hari).

Hasil penelitian Neves \& Alves (2004) menunjukkan bahwa penempelan konidia $M$. anisopliae pada kutikula Cornitermes cumulans (Kollar) (Isoptera: Termitidae) terjadi antara 6 jam setelah aplikasi. Perkecambahan mulai terjadi 6 jam setelah aplikasi dan penetrasi terjadi 12 jam, tanpa atau dengan pembentukan apresorium. Selama periode antara 24 jam dan 72 jam setelah inokulasi $M$. anisopliae mungkin mengkolonisasi serangga. Kebanyakan serangga mati (hingga 80\%) antara 72 jam dan 96 jam setelah inokulasi.

Pupa $C$. cramerella yang mati tubuhnya mengeras, miselium berwarna putih pada awalnya akan menyelimuti tubuh pupa $C$. cramerella, dan lama kelamaan warna tersebut akan berubah menjadi hijau (Gambar 2).

\section{Sporulasi Metarhizium spp. pada Tubuh Pupa $C$.}

Cramerella. Pengamatan sporulasi Metarhizium spp. pada tubuh pupa C. cramerella setelah dilakukan moist chamber selama 7 hari menunjukkan bahwa tidak ada perbedaan nyata antar isolat yang diuji $(\mathrm{F}=0,6, \mathrm{db}=$ $8 ; 18, \mathrm{P}=0,7692$ ) (Tabel 4).

Sporulasi jamur Metarhizium spp. pada tubuh pupa $C$. cramerella setelah 7 hari inkubasi pada moist chamber, yang tertinggi dihasilkan oleh isolat MetHKo $(93,33 \%)$ dan terendah pada isolat MetApBm (60\%). Pertumbuhan dan perkembangan jamur entomopatogen terutama dipengaruhi oleh kondisi lingkungan khususnya kelembaban yang tinggi dan temperatur yang sesuai untuk bersporulasi. Hal ini seperti dikemukakan oleh Arthurs \& Thomas (2001) yang menunjukkan bahwa kelembaban relatif yang tinggi (96\%) dibutuhkan untuk sporulasi $M$. anisopliae var. acridum pada tubuh

Tabel 3. Nilai LT50 berbagai isolat Metarhizium spp.

\begin{tabular}{lc}
\hline Isolat & LT50 (SK 95\%) (hari) \\
\hline MetApCi & $3,04(1,60-4,11)$ \\
MetKbCi & $3,13(1,82-4,25)$ \\
MetHKo & $3,51(2,04-4,65)$ \\
MetAKo & $3,58(2,47-4,40)$ \\
MetApKb & $3,62(2,32-4,65)$ \\
MetLkKo & $3,99(2,71-5,01)$ \\
MetApBd & $4,28(2,99-5,54)$ \\
MetPKo & $4,48(2,85-6,87)$ \\
MetApBm & $4,82(3,41-6,09)$ \\
\hline
\end{tabular}
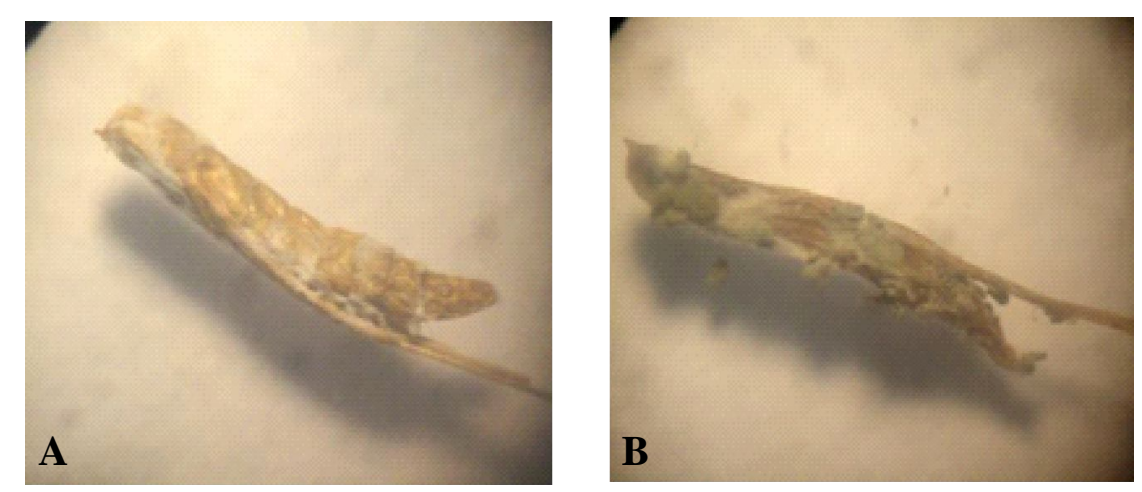

Gambar 2. Tubuh pupa C. cramerella yang diselimuti miselium Metarhizium spp. pada perbesaran 40x ( $\mathrm{A}=3$ hari setelah inkubasi, $\mathrm{B}=7$ hari setelah inkubasi dengan metode moist chamber). 
Schistocerca gregaria. Menurut Santoso (1993) jamur tidak selalu tumbuh keluar menembus integumen serangga inang. Apabila keadaan kurang mendukung, perkembangan jamur hanya berlangsung di dalam tubuh serangga. Sporulasi pada ubuh serangga ini penting untuk infeksi dan pemencaran konidia.

Imago Terbentuk. Mortalitas pupa $C$. cramerella berpengaruh terhadap persentase imago terbentuk. Persentase imago terbentuk hingga akhir pengamatan ( 8 hari setelah inokulasi) tidak berbeda nyata antar isolat tetapi berbeda nyata antara isolat-isolat dengan kontrol $(\mathrm{F}=15,8 ; \mathrm{db}=9,20 ; \mathrm{P}=0,0000)$. Setelah dilakukan uji lanjut Tukey (HSD) 5\% hasilnya dapat dilihat pada Tabel 5.

Semakin banyak pupa yang mati, maka semakin sedikit pula imago terbentuk. Pengamatan terhadap mortalitas pupa $C$. cramerella hingga 8 hari setelah aplikasi menunjukkan bahwa seluruh pupa $C$. cramerella yang tidak mati pada uji patogenisitas bermetamorfosis menjadi imago. Namun imago yang terbentuk tidak semuanya normal. Ada imago yang cacat. Bahkan pada imago yang cacat ini terjadi sporulasi Metarhizium spp. setelah imago tersebut diinkubasi pada moist chamber. Imago yang cacat menunjukkan pembentukan sayap yang kurang sempurna. Sayapsayap ini seperti masih terbungkus selaput, sehingga tidak bisa terentang (Gambar 3). Hal ini menunjukkan bahwa isolat Metarhizium spp. yang diuji selain merusak pada stadia pupa $C$. cramerella juga merusak pada stadia imago. Hasil penelitian Trizelia et al. (2010) juga menunjukkan bahwa infeksi Metarhizium spp terhadap larva Crocidolomia pavonana berpengaruh terhadap persentase imago yang terbentuk dan dapat menghambat pembentukan imago sampai $71 \%$ tergantung pada sumber isolat.

Imago $C$. cramerella yang cacat akhirnya mati juga karena terinfeksi Metarhizium spp. Hal ini diduga terkait dengan akibat lanjut dari mikotoksin yang dihasilkan Metarhizium spp. Samsinokova (1968) cit. Kurnia (1998) menyatakan bahwa toksin yang dihasilkan

Tabel 4. Sporulasi jamur Metarhizium spp. pada tubuh pupa C. cramerella setelah 7 hari inkubasi

\begin{tabular}{lc}
\hline Isolat & Rata-rata sporulasi pada tubuh pupa C. cramerella $(\%) \pm$ SD \\
\hline MetHKo & $93,33 \pm 5,77$ \\
MetApCi & $90,00 \pm 10,00$ \\
MetApKb & $90,00 \pm 17,32$ \\
MetLkKo & $86,67 \pm 15,28$ \\
MetKbCi & $76,67 \pm 20,82$ \\
MetPKo & $66,67 \pm 11,55$ \\
MetApBd & $66,67 \pm 5,77$ \\
MetAKo & $66,67 \pm 57,74$ \\
MetApBm & $60,00 \pm 52,92$ \\
\hline
\end{tabular}

Tabel 5. Persentase imago C. cramerella yang terbentuk setelah aplikasi Metarhizium spp.

\begin{tabular}{lc}
\hline Isolat & Rata-rata imago terbentuk $(\%) \pm$ SD \\
\hline Kontrol & $83,33 \pm 5,77 \mathrm{a}$ \\
MetPKo & $30,00 \pm 10,00 \mathrm{~b}$ \\
MetApBd & $20,00 \pm 10,00 \mathrm{~b}$ \\
MetApBm & $16,67 \pm 15,28 \mathrm{~b}$ \\
MetKbCi & $13,33 \pm 11,55 \mathrm{~b}$ \\
MetLkKo & $10,00 \pm 10,00 \mathrm{~b}$ \\
MetHKo & $6,67 \pm 5,77 \mathrm{~b}$ \\
MetApKb & $6,67 \pm 11,55 \mathrm{~b}$ \\
MetAKo & $3,33 \pm 5,77 \mathrm{~b}$ \\
MetApCi & $3,33 \pm 5,77 \mathrm{~b}$ \\
\hline
\end{tabular}

Angka yang diikuti huruf yang sama dalam kolom yang sama menunjukkan tidak berbeda nyata menurut uji Tukey (HSD) pada $\alpha=0,05$. 

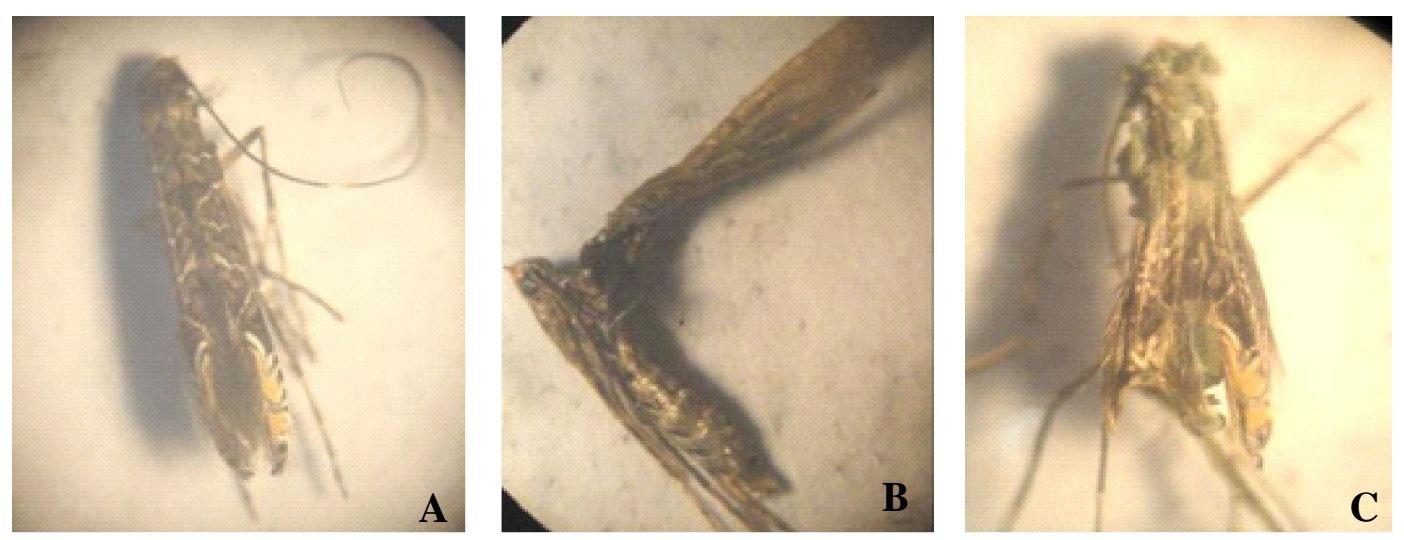

Gambar 3. Imago C. cramerella pada perbesaran 40x. $\mathrm{A}=$ imago normal, $\mathrm{B}=$ imago cacat, dan $\mathrm{C}=$ imago terinfeksi Metarhizium spp.

jamur entomopatogen dapat merusak secara langsung fungsi utama tubuh terutama fungsi hormon (hormon pergantian dan pembentukan kulit). Akibat infeksi dan pemanfaatan cairan tubuh serangga inang oleh jamur maka proses pembentukan integumen baru (integumen imago) tidak berjalan sempurna sehingga imago tersebut tidak mampu bertahan hidup lebih lama.

\section{SIMPULAN}

Isolat Metarhizium spp. yang berasal dari rizosfer dapat mematikan pupa C. cramerella sampai $96,67 \%$ dan menghambat pembentukan imago $C$. cramerella. Isolat MetApCi yang berasal dari rizosfer cabai merupakan isolat virulen terhadap pupa $C$. cramerella.

\section{DAFTAR PUSTAKA}

Arthurs S \& Thomas MB. 2001. Effect of temperature and relative humidity on sporulation of $M$. anisopliae var. acridium in mycosed cadavers of Schistocerca gregaria. J. Inv. Pathol. 78 : 59-65.

Barnett HL \& Hunter BB. 1972. Illustrated Genera of Imperfect Fungi. Third Edition. Burges Publishing Company, Minneapolis.

Daoust RA \& Roberts DW. 1982. Virulence of natural and insect-passaged strains of Metarhizium anisopliae to mosquito larvae. J. Inv. Pathol 40: 107-117.

Depparaba F. 2002. Penggerek buah kakao (Conopomorpha cramerella Snell.) dan penanggulangannya. Jurnal Litbang Pertanian 21(2) : 69-74.
Desyanti, Hadi YS, Yusuf S, \& Santoso T. 2007. Keefektifan beberapa spesies cendawan entomopatogen untuk mengendalikan rayap tanah Captotermes gestroi Wasmann (Isoptera: Rhinotermitidae) dengan metode kontak dan umpan. J. Ilmu \& Teknologi Kayu Tropis 5(2): 68-77.

Disbun Sumbar. 2011. Laporan Triwulan ITahun 2011 Serangan Organisme Pengganggu Tumbuhan (OPT) pada Komoditi Kakao. Dinas Perkebunan Sumatera Barat, Padang.

Ferron P. 1981. Pest control by fungi Beauveria and Metarhizium. Di dalam: Burges HD, editor. Microbial Control of Pests and Plant Diseases 1970-1980. London: Academic Press Inc. hlm. 465-482.

Ginting S. 2008. Patogenisitas Beberapa Isolat Cendawan Entomopatogen terhadap Rayap Tanah Coptotermes curvignathus Holmgren dan Schedorhinotermes javanicus Kemmer (Isoptera : Rhinotermitidae). [Tesis]. Institut Pertanian Bogor, Bogor.

Hamdani. 2008. Keanekaragaman Jamur Entomopatogen pada Rhizosfer Kakao dan Patogenesitasnya terhadap Hama Penggerek Buah Kakao (Conopomorpha cramamerella).[Tesis]. Universitas Andalas, Padang.

Kurnia D. 1998. Efektivitas Beauveria bassiana (Balsamo) Vuillemin dan Metarhizium anisopliae (Metchnikoff) Sorokin serta Kombinasi Keduanya terhadap Larva Spodoptera litura F (Lepidoptera: Noctuidae). [Skripsi]. Universitas Andalas, Padang. 
Neves PMOJ \& Alves SB. 2004. External events related to the infection process of Cornitermes cumulans (Kollar) (Isoptera: Termitidae) by the entomopathogenic fungi Beauveria bassiana and Metarhizium anisopliae. Neotropical Entomology 33(1): 051-056.

Prayogo Y \& Tengkano W. 2004. Pengaruh konsentrasi dan frekuensi aplikasi Metarhizium anisopliae isolat kendalpayak terhadap tingkat kematian Spodoptera litura. Sainteks. Jurnal Ilmiah Ilmu-Ilmu Pertanian 3 (10) : 209-216.

Santoso T. 1993. Dasar-dasar patologi serangga. Di dalam: Simposium Patologi Serangga I. Prosiding Makalah Simposium Patologi Serangga I. Yogyakarta. 12-13 Oktober 1993. Yogyakarta: Himpunan Entomologi Indonesia Cabang Yogyakarta. hlm. 1-15.

Sulistyowati E. 2009. Pengendalian Hama. Dalam: Wahyudi T, Panggabean TR, \& Pujianto (Ed.). Panduan Lengkap Kakao: Manajemen Agribisnis dari Hulu hingga Hilir. Penebar Swadaya, Jakarta.
Suntoro, Bahri AS, \& Budiman. 2003. Studi pemerangkapan pupa PBK dengan menggunakan daun kakao. Risalah Simposium Nasional Penelitian PHT Perkebunan Rakyat. Bogor, 17-18 September. 189-192.

Tanada Y \& Kaya HK. 1993. Insect Pathology. San Diego: Academic Press, INC. Harcourt Brace Jovanovich, Publisher.

Trizelia, Syam U, \& Herawati Y. 2010. Virulensi isolat Metarhizium sp. yang berasal dari beberapa rizosfer tanaman terhadap Crocidolomia pavonana Fabricius (Lepidoptera: Pyralidae). Manggaro 11(2): 51-56

Wahyudi T \& Misnawi. 2007. Fasilitas Perbaikan Mutu dan Produktivitas Kakao Indonesia. Warta Pusat Penelitian Kopi dan Kakao Indonesia 23(1) : 32-43.

Wardoyo S. 1982. The cocoa pod borer. A major hindrance to cocoa development. Indonesian Agriculture Research Development Journal 2 (1): 1-4. 